\title{
Tsunami response system for ports in Korea
}

\author{
H.-R. Cho, J.-S. Cho, and Y.-S. Cho \\ Department of Civil and Environmental Engineering, Hanyang University, 222 Wangsimni-ro, \\ Seongdong-gu, Seoul 133-791, Korea \\ Correspondence to: Y.-S. Cho (ysc59@ hanyang.ac.kr) \\ Received: 30 December 2014 - Published in Nat. Hazards Earth Syst. Sci. Discuss.: 25 March 2015 \\ Revised: 8 July 2015 - Accepted: 18 August 2015 - Published: 9 September 2015
}

\begin{abstract}
The tsunamis that have occurred in many places around the world over the past decade have taken a heavy toll on human lives and property. The eastern coast of the Korean Peninsula is not safe from tsunamis, particularly the eastern coastal areas, which have long sustained tsunami damage. The eastern coast had been attacked by 1983 and 1993 tsunami events. The aim of this study was to mitigate the casualties and property damage against unexpected tsunami attacks along the eastern coast of the Korean Peninsula by developing a proper tsunami response system for important ports and harbors with high population densities and high concentrations of key national industries. The system is made based on numerical and physical modelings of 3 historical and 11 virtual tsunamis events, field surveys, and extensive interviews with related people.
\end{abstract}

\section{Introduction}

The rapid growth of the Korean economy is largely due to international trade facilitated by its geographical advantage of being a peninsula with unlimited ocean access. The establishment of a nationwide disaster prevention system to ensure this continued national prosperity is becoming increasingly important for marine industries, coastal logistics facilities, and the safety of coastal residents. The major seaports of Korea and their surrounding areas frequently suffer extensive damage from marine disasters, such as tsunamis, seawater flooding, and typhoons. Therefore, a national disaster response system for effective disaster prevention and for damage mitigation urgently needs to be established by predicting disasters that are likely to occur by using case studies of past disasters around the Korean coasts and their cause analysis.
Of all of the types of marine disasters, tsunamis are one of the worst in terms of the scope of casualties and property damage that they can cause. It is of vital importance to establish effective prevention, because tsunamis occur suddenly and leave behind massive devastation (Cho, 1995). The most effective method for coping with the risk of tsunamis is an emergency action plan (hereinafter referred to as EAP). An EAP is made to provide protection of lives of people and to minimize property loss from natural disasters by addressing the hazards and damage outcomes that are likely to occur. The tsunami countermeasures currently in place in Korea include designated tsunami evacuation routes and shelters with escape route signs erected on every street corner along the east coast. Local authorities in these regions are equipped with an EAP in the form of a printed "Manual for Onsite Management of Earthquake Disasters" to ensure the rapid implementation of safety and evacuation measures before the arrival of the first tsunami. However, since the current response system is focused on villages and cities, it is necessary to set up a separate tsunami hazard and damage mitigation plan for ports and harbors as part of the national infrastructure.

In Korea, several ports located along the eastern coast had been attacked by historical tsunami events. For example, the Central East Sea Tsunami occurred on 26 May 1983 caused damage at Imwon Port and casualties: death 1, disappearance 2 , injury 2 ; houses damaged or destroyed 23 , flood damage 21. The run-up heights of about 3-4 $\mathrm{m}$ had been observed along the eastern coast of the Korean Peninsula. Although there were no casualties of due to the Hokkaido Tsunami which occurred on 12 July 1993, many houses and fish boats had been wrecked and about $3 \mathrm{~m}$ run-up heights had been observed (Cho et al., 2004; Sohn et al., 2009). Figure 1 shows three source locations of undersea earthquakes responsible 


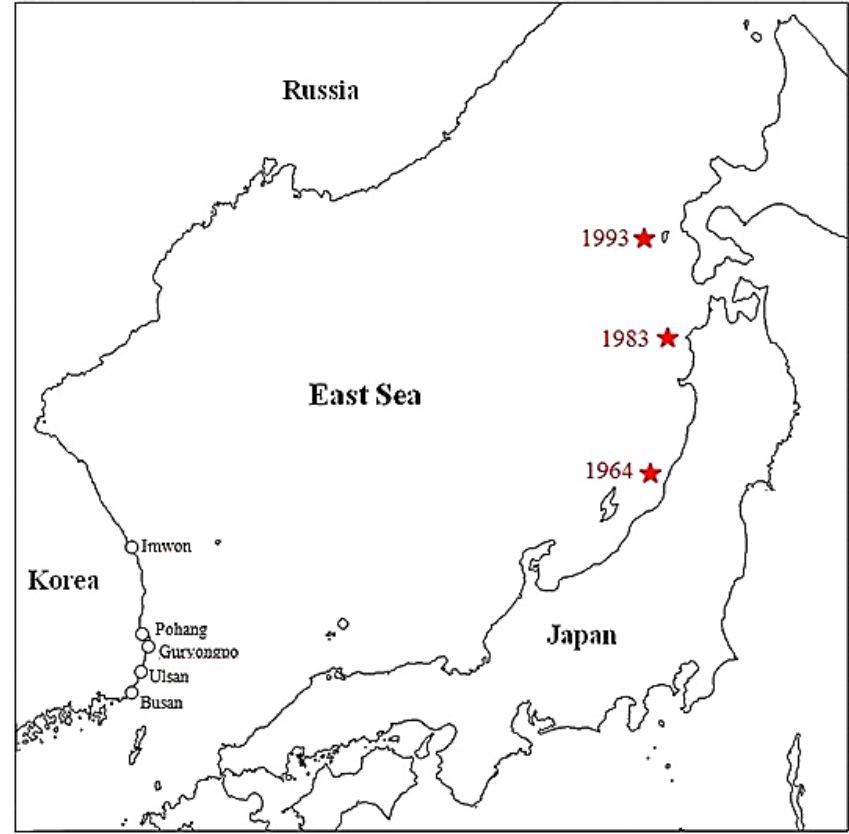

Figure 1. Locations of ports and earthquake sources for three major historical tsunamis.

for 1964, 1983 and 1993 historical tsunami events, respectively. The figure also describes several ports located along the eastern coast of the Korean Peninsula.

Figure 2 displays the arrival time of the leading parts of the Central East Sea Tsunami. The arrival time is estimated by a numerical model based on the shallow-water theory (Cho and Yoon, 1998). As shown in the figure, the leading parts reach the eastern coast of Korea after 90-120 min. Thus, the authority may have $90-120 \mathrm{~min}$ to prepare for the disaster. In Korea, the Korea Meteorological Agency (KMA) is in charge of the first warning of a tsunami (http://www.kma.go.kr) and the Ministry of Public Safety and Security is in charge of emergency preparedness and civil defense (http://www.mpss. go.kr). In general guidelines, $30 \mathrm{~min}$ is specified to prepare against any tsunami strike triggered by undersea earthquakes off the western coast of Japan.

The focus of this study was the establishment of a tsunami response system for major ports on the eastern coast of the Korean Peninsula. The system was designed to be uniquely tailored to each port by having individual ports and their respective local authorities participate in formulating their own EAPs.

\section{Tsunami response system}

A port-related EAP should be designed in order to ensure the protection of human lives from an unexpected tsunami, to minimize property loss, and to maximize the speed of the post-disaster restoration of harbor facilities in order for nor-

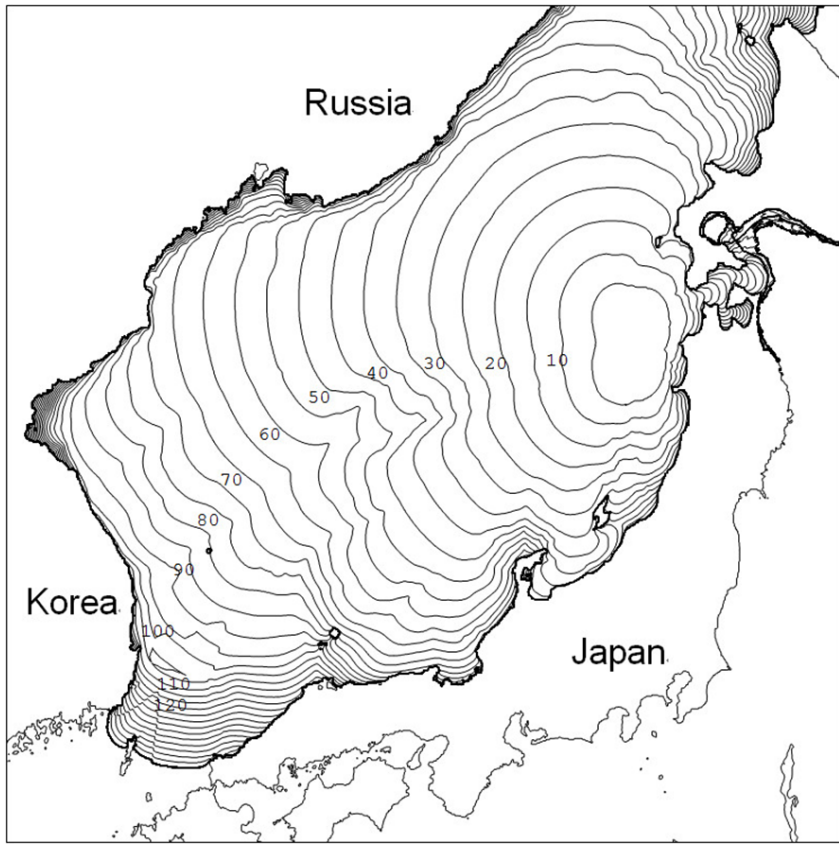

Figure 2. Predicted arrival time of leading tsunamis (unit: min).

mal operations to resume. The aim of this study was to set up a tsunami response system by establishing a concrete EAP tailored to individual seaports pursuant to Article 31 of the Enforcement Decree of the "Countermeasures against Natural Disasters Act" as listed in Table 1.

In order to tailor a disaster response system for each specific port, the geographical features of the corresponding region should be considered. To this end, we conducted field surveys at the several ports as well as their respective surrounding areas on the east coast. We created concrete EAPs based on the structures and characteristics of the moored ships at the individual ports, and prepared guidelines for the port facilities and these moored ships.

\subsection{Tasks according to disaster response steps}

In the event of a tsunami, port authorities (local governing bodies or the Regional Maritime Affairs and Port Administration) can execute basic tasks and EAPs most effectively by performing the action plan tasks item by item in accordance with the progression of the tsunami. In addition, when assessing the tsunami-related meteorological information of a disaster event, local governments that are responsible for port administration should retain disaster response task forces in order to ensure rapid and accurate execution of the EAPs.

First, the task manual for port authorities should be drafted and divided into the following five steps according to the stage of the tsunami: (i) pre-event, (ii) intra-event, (iii) postevent, (iv) end of situation, and (v) restoration. In addition to a description of the roles expected of public authorities and official institutions, such as the local governments, dur- 
Table 1. Enforcement ordinance of countermeasures against natural disasters Act, Article 31.

1. EAP for residents and related organizations

2. Emergency action methods in an emergency

3. Analysis of emergency situations and propagation aspect of floods

4. Expected flood map

5. Warning system

6. Emergency evacuation plan

7. Plan for accommodating victims

8. Joint response system of related organizations and groups

9. Other needs for emergency response, such as traffic control in at risk areas

ing a tsunami, a detailed step-by-step code of conduct for evacuees was also drafted. These details enhance the utility of the manual by including all of the institutions and individuals involved in the disaster event. The manual covered areas including: traffic and transport measures; supply of food and goods; medical assistance; epidemiological measures, including quarantine, death care, and supply of relief goods; mobilization networks for the implementation of the emergency response measures; responsibilities and tasks of port authorities; guidelines for ship owners and operators as well as regional fishery workers and evacuees from the port areas; guidelines to minimize property damage from tsunamis; and Pertinent training and education.

The following is a simple example of an EAP guideline for each authority or individual in charge. Different codes of action were applied to normal times and warning periods. The focus during normal times was continuous preparedness against tsunamis, whereas rapid response and evacuation were the top priorities during a warning period.

\section{Fishery}

The normal time guidelines for those engaged in the fishery industry consisted of forming a ship group and working within mutually visible distances, while maintaining ship-to-ship communication and fishing-related safety regulations. In addition, it was determined that workers should remain informed of the weather forecast and maintain connections with the telecommunication networks of pertinent institutions, enabling them to promptly ask fishery communication stations for rescue if a marine accident occurred. Safe shelters on land for small vessels should be allocated beforehand in order to facilitate rapid evacuation. Regular safety checks, maintenance and repair of old equipment should be performed alongside state checks of the water intake and drainage facilities, vinyl houses, and emergency power generators.
The code of action that should be adhered to when a tsunami warning is in effect is as follows: vessels within a reachable distance of open seas exceeding $400 \mathrm{~m}$ in depth should immediately navigate offshore (UNESCOIOC and ITIC, 2009), and small vessels should immediately be rescued and towed to a safe place with the maximum mobilization of salvage equipment and crews; fishing nets and other fishing gear should be sunk by cutting the lines or hauled away if they are difficult to cut; vessels should be safely evacuated following the instructions of the fishery telecommunication station and fishing gear stored in wharves and fishing boats should be moved to sheltered places on land; measures to avoid collisions among ships moored in harbors should be taken in order to prevent damage and losses; and transportable farm materials and offshore working platforms should be moved to protected places.

\section{Ship owners}

The normal time guidelines for ship owners and related staff consist of the following measures: ships should be kept ready for emergency situations by means of regular checks of the telecommunication equipment and safety devices, in addition to safety inspections and maintenance of the vessel hulls and engines; measures should be taken to prevent hulls from being damaged by collisions with other vessels; and meteorological data and tsunami signals should be checked. As soon as a tsunami warning is issued, the following courses of action should be taken: ships should be steered away from the zone of influence of a tsunami; damage to the hull should be prevented by taking precautionary measures, such as incorporating cushioning materials in order to minimize the impact of collisions with other ships; navigation information, including records of leaving and entering a harbor, should be traceable; and vessels at berth should be dislocated following the directions of the port authority or evacuated to deep, open sea. 


\section{Port personnel}

The normal time guidelines for port personnel consist of the following measures: maintenance and management of warehouses, open storage areas, lights, and water supply facilities in preparedness for tsunamis; regular safety checks of old equipment; simple reinforcement of existing structures in the region by contractors in order to minimize any potential damage; and periodical tsunami evacuation drills in coordination with civil defense drills.

The guidelines during a tsunami include the following actions: disseminating evacuation instructions to atberth ships within the harbor area; towing and mooring ships from at-sea repair and maintenance facilities; taking measures to prevent damage to cargo-handling equipment; keeping flood-prone areas under surveillance; and reinforcing construction sites.

\section{Local residents}

Local residents should also be prepared for tsunamis in accordance with the following guidelines: during normal times, they should minimize the potential risks from tsunamis by fastening signboards and roofs, and removing or fastening any other objects at risk of falling; coastal embankments and other safety facilities should be constantly checked and kept in a functional state; and residents should always participate in tsunami evacuation drills so that rapid evacuation can be ensured as soon as a tsunami warning is issued.

The following tasks should be performed during an evacuation: children, pregnant women, and elderly persons should be escorted to the shelters first; in disasterand flood-prone areas, such as lowland and habitual inundation areas, evacuations should be performed more rapidly; basements of buildings that are expected to flood should be sealed immediately; and traffic on coastal roads should be restricted in order to prevent damage.

\subsection{Emergency management task implementation system}

In Korea, important ports and harbors are administered by their respective authorities. Each port authority has its own emergency management task implementation system. The aim of this study was to formulate a master emergency response system by establishing a task implementation system that integrated port authorities with the local governing bodies of the neighboring regions. The role of a port authority is assumed by either the Regional Maritime Affairs and Port Administration or by the municipal and provincial offices. The Regional Maritime Affairs and Port Administration oversees 14 of the country's major trade ports.
Each port authority has created its own task implementation system for effective emergency management in situations such as disastrous events and run its own regional accident response center. Other ports and harbors are administered by their respective municipal or provincial offices. Each municipal or provincial office plans for natural disasters, such as tsunamis, by producing guidelines as a part of the Natural Disaster Emergency Assistance Plan pursuant to Article 36 of the Countermeasures against Natural Disasters Act. Each port authority has its own emergency management task implementation system with different emphases. While the scope of tasks of the Regional Maritime Affairs and Port Administration is limited to affairs relevant to harbors, such as port management and facility protection, the focus of municipal and provincial offices is placed on preventing loss of life and property, as well as providing emergency assistance.

Therefore, it is necessary to ensure a thorough understanding and a coordinated cooperative system between the Regional Maritime Affairs and Port Administration and the municipal and provincial offices. In this regard, our field surveys of these two organizations revealed that, in some cases, they did not have a precise understanding of their mutual tasks or mistook their tasks as the other's responsibility and vice versa. In response to this, and in order to avoid the aggravation of damage due to inadequate disaster management, we also compared the task implementation system of an Emergency Response Center of the Regional Maritime Affairs and Port Administration with that of a Disaster and Safety Management Center of a municipal and/provincial office in this study, and we delineated the tasks by department.

\section{Port Emergency Action Plan (EAP)}

\subsection{Port information}

Basic information about a port should be included when setting up an EAP. Including information on a port in a manual is required, because it enables a rapid response by the central disaster headquarters through immediate access to basic information about the risk-exposed harbor, in addition to ensuring an effective response by establishing a disaster response system at the regional institutions and authorities of concern. This basic information should include major port facilities, such as wharves, breakwaters, quay walls, and oil tanker jetties; the location information and views from the harbor; the types of cargo handled; and the wharf names. It is also necessary to provide information about the surrounding marine environment. For example, Table 2 provides basic information of port and marine environment at Ulsan Port.

\subsection{Communication systems among key organizations}

An EAP should include emergency communication systems among the primary authorities of concern. Setting up a communication network containing the names and contact de- 
Table 2. The basic information at Ulsan Port.

\begin{tabular}{llll}
\hline Design wave height & Design wave direction & Approx. H.H.W. & M.S.L. \\
\hline $10.20 \mathrm{~m}$ & SSW & $0.605 \mathrm{~m}$ & $0.303 \mathrm{~m}$ \\
\hline Breakwater & Pier & Lighters Wharf & Berthing Capacity \\
\hline $4279 \mathrm{~m}$ & $24159 \mathrm{~m}$ & $9604 \mathrm{~m}$ & 123 ships \\
\hline
\end{tabular}

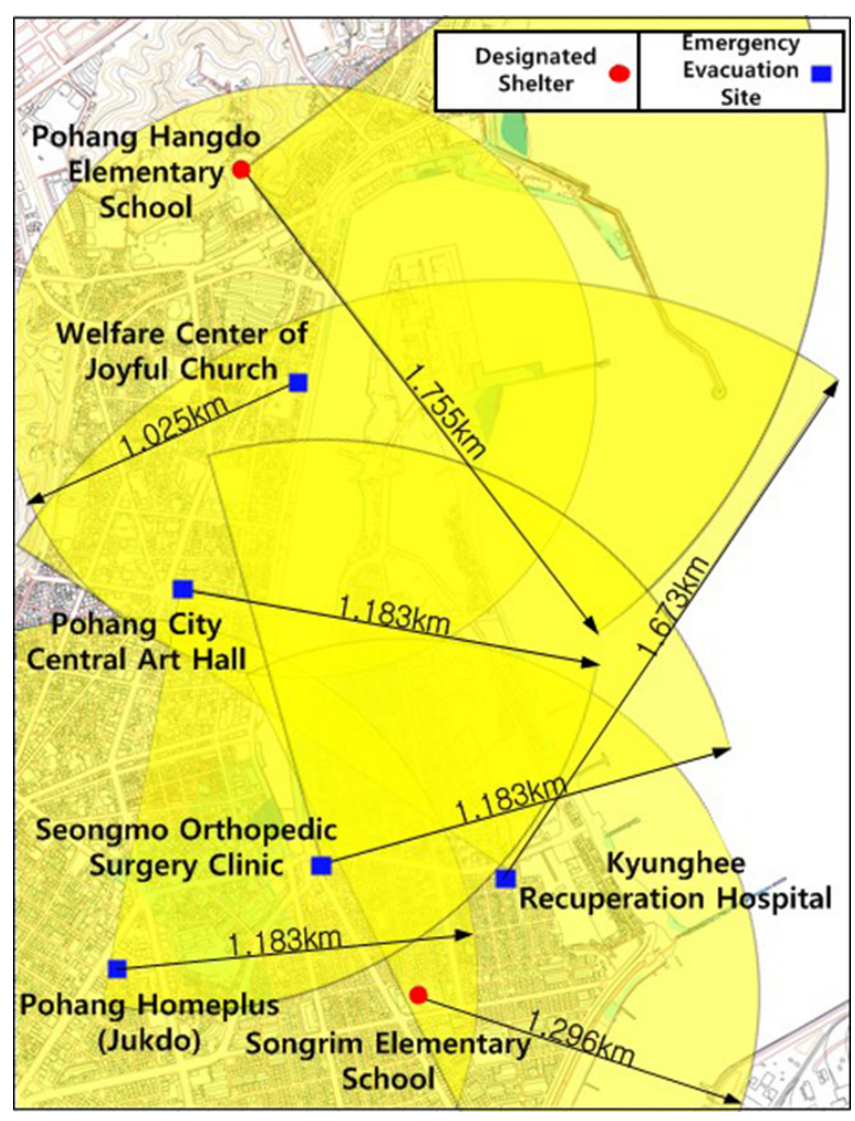

Figure 3. Shelter coverage areas at Pohang Port.

tails of the organizations and individuals involved in the port facility operations and administration is crucial to ensuring prompt communication in emergency situations. The primary facilities include tsunami warning terminals and emergency situation warning systems, harbors, fishery facilities, roads, and railroads. Harbors fall under the jurisdiction of their respective municipal and provincial offices, the Department of Marine Affairs, or the Regional Maritime Affairs and Port Administration. The municipal and provincial offices are in charge of roads, and the Korean Railroad Corporation is responsible for the railroads.

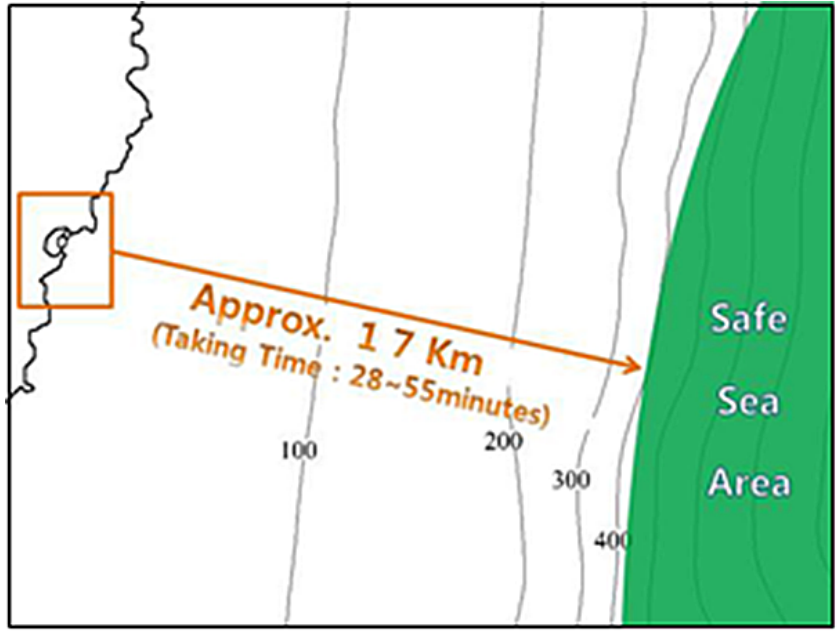

Figure 4. Distance to safe sea area at Guryongpo Port.

\subsection{Communication networks for key lifelines}

A tsunami can not only cause casualties and property loss, but it can also cause secondary damage from the destruction of lifeline facilities vital to daily life, such as the supply lines for electric power, natural gas, water, and communication. The destruction of high-risk facilities, such as gas lines and oil pipelines, can increase the loss of life and property due to fires. Therefore, the restoration of damaged lifelines should also be a top priority alongside the disaster response efforts and a well-functioning communication network among the institutions involved during a tsunami should be maintained, while their respective tasks should be predetermined and well understood.

The institutions in charge of lifeline facilities should never fail to perform the following tasks. In the case of power supplies, authorities must maintain information sharing and cooperation systems. In addition, they must take countermeasures against a potentially snowballing crisis by setting up a stage-by-stage response system in accordance with the emergency levels. The authorities in charge of gas supplies should be prepared for emergency situations by establishing a coordinated cooperative system with the governing bodies as well as an emergency communication network. Oil refinery-related organizations should take emergency countermeasures depending on the actual disaster type and stages 
Table 3. Main information for tsunami shelters at Pohang Port.

\begin{tabular}{|c|c|c|c|c|c|c|}
\hline Type & Building Name & $\begin{array}{l}\text { Distance } \\
(\mathrm{m})\end{array}$ & $\begin{array}{l}\text { Evacuation time } \\
\text { (based on an } \\
\text { adult male) }\end{array}$ & $\begin{array}{l}\text { Height } \\
\text { (floors) }\end{array}$ & $\begin{array}{l}\text { Capacity } \\
\text { (persons) }\end{array}$ & Subsidiary facility \\
\hline \multirow{2}{*}{$\begin{array}{l}\text { Designated } \\
\text { Shelter }\end{array}$} & Pohang Hangdo Elementary School & 500 & $7 \mathrm{~min}$ & 4 & 1100 & Washing, cooking, lodging \\
\hline & Songrim Elementary School & 700 & $10 \mathrm{~min}$ & 4 & 1200 & Washing, cooking, lodging \\
\hline \multirow{5}{*}{$\begin{array}{l}\text { Emergency } \\
\text { Evacuation } \\
\text { Site }\end{array}$} & $\begin{array}{l}\text { Welfare Center of } \\
\text { Joyful Church }\end{array}$ & 30 & $2 \min$ & 5 & 1500 & Washing \\
\hline & $\begin{array}{l}\text { Pohang City } \\
\text { Central Art Hall }\end{array}$ & 400 & $7 \mathrm{~min}$ & 4 & 500 & Washing \\
\hline & $\begin{array}{l}\text { Pohang Homeplus } \\
\text { (Jukdo) }\end{array}$ & 700 & $10 \mathrm{~min}$ & 4 & 2000 & Washing \\
\hline & $\begin{array}{l}\text { Seongmo Orthopedic Surgery } \\
\text { Clinic }\end{array}$ & 50 & $2 \min$ & 5 & 500 & Washing \\
\hline & Kyunghee Recuperation Hospital & 100 & $3 \min$ & 7 & 1000 & Washing, cooking, lodging \\
\hline
\end{tabular}

by procuring an overview of the emergency situation, such as the supply-demand discrepancies under government control as well as the rises in oil price and their duration. The telecommunication service institution should establish a rapid and unified response system by implementing disaster response headquarters in case there are communication service failures due to a large-scale disaster. The institutions in charge of water supply systems should ensure an uninterrupted potable water supply by maintaining their systems and promptly restoring any destroyed water lines during emergency situations.

\subsection{Included addresses for disaster reporting and medical services}

A disastrous event and related information should be disseminated to the public as quickly and widely as possible. A disastrous event should be reported to the disaster headquarters or the fire departments of the corresponding municipal or provincial offices as well as the local or maritime police station emergency desks and local broadcasters. We also included the addresses of the medical service providers near each port and marked their locations on a hazard map in order to enable rapid emergency medical assistance and to enhance the efficacy of patient transportation. In terms of healthcare service providers, the large hospitals in the vicinity of ports are recommended, because they are able to handle the simultaneous treatment of a large numbers of patients, including surgical interventions, and they also provide mortuary services.

\subsection{Port shelters and evacuation routes}

The accommodation capacity, which is the number of people that can be accommodated, is an important factor to consider when choosing a shelter. This value is obtained by measur- ing the total surface area of a shelter space and it is expressed as the shelter space per unit surface area. According to a report from the Japanese Review Committee of the Japanese Tsunami Response Manual (2002), the accommodation capacity per unit area is determined in proportion to the population density and it is specified as 1 person $\mathrm{m}^{-2}$ or 2 persons $\mathrm{m}^{-2}$. In the current study, the unit area for the buildings was set as the gross habitable area from the third floor (safe from water infiltration) to the top floor. In the case of emergency shelters such as mountains, the entire surface area used for the shelter was set as the unit area.

Estimating the accommodation capacity in terms of the length and range is important for a smooth and efficacious evacuation in emergency evacuation situations, and it is one of the major factors to be considered when choosing a shelter. The accommodation capacity is expressed as the length of the shelter's range as a circular form. A simple formula for estimation of the accommodation capacity is expressed as follows (Japanese Review Committee of Tsunami Response Manual, 2002):

$L=\sqrt{\frac{A / D}{\pi} \times P}$,

where $L$ is the shelter length (range), $A$ is the number of evacuees, and $D$ is the population density of the corresponding region (persons $\mathrm{m}^{-2}$ ). The value of $P$ is 1,2 , or 4 when the shape of the shelter is a circle, semi-circle, or quadrant, respectively.

As shown in Fig. 3, when we mapped the areas of the designated and emergency shelters, we overlapped these locations in order to cover the entire port and its surrounding area. This enables people to reach a shelter from anywhere in the port's vicinity. Table 3 displays the important information for each shelter, including the name of the building, the distance from the coastline, the expected time for evacuation, and the 

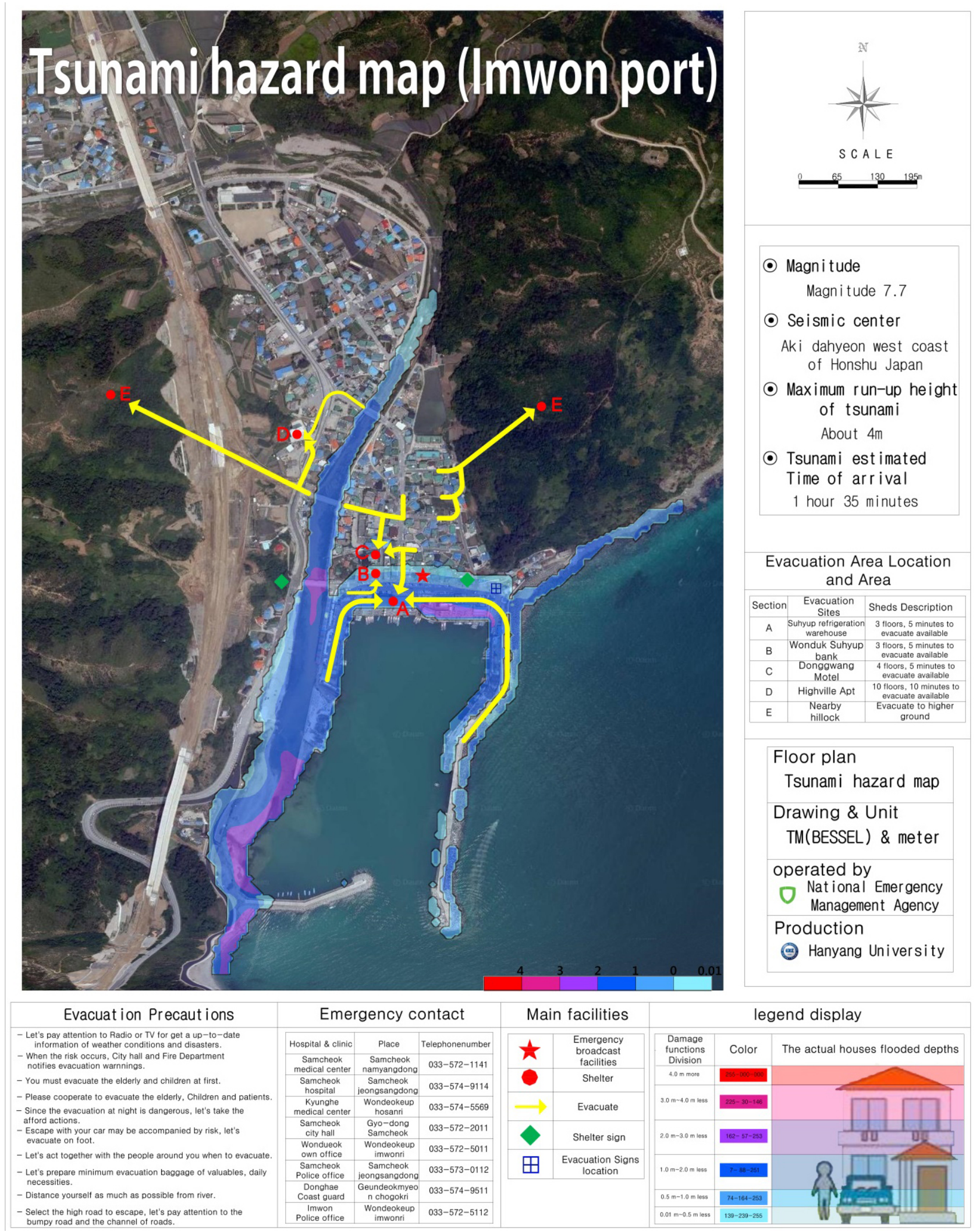

Figure 5. Tsunami hazard map at Imwon Port. 
Table 4. The system of the vessel traffic services center at Busan Port.

\begin{tabular}{llll}
\hline Call name & Channel no (VHF) & Purpose & Phone number \\
\hline Busan VTS & CH 12 & $\begin{array}{l}\text { VTS business } \\
\text { (North Port, Yongho Bay, } \\
\text { Traffic safety at certain waters) }\end{array}$ & (05-2735 \\
\cline { 2 - 3 } & CH 09 & $\begin{array}{l}\text { VTS business } \\
\text { (Anchorage, Gamcheon Port, Dadaepo) }\end{array}$ & $\begin{array}{l}\text { Assistance Channel for Traffic Service } \\
\text { (CH 12 when communication is busy) }\end{array}$ \\
\cline { 2 - 4 } CH 11 & Broadcasting for Navigation Safety and Information \\
\cline { 2 - 4 } CH 06 16 & $\begin{array}{l}\text { Call and response, } \\
\text { emergency communications }\end{array}$ \\
\hline
\end{tabular}

Table 5. Frequency of fishery telecommunication stations at Busan Port and Ulsan Port

\begin{tabular}{rr}
\hline Busan $(\mathrm{kHz})$ & Ulsan $(\mathrm{kHz})$ \\
\hline 2116.4 & 2518.4 \\
4612.4 & 4477.4 \\
8114.4 & 27857.4 \\
2450.4 & 27886.4 \\
2596.4 & \\
27806.4 & \\
27886.4 & \\
\hline
\end{tabular}

accommodation capacity. The time for evacuation was determined by conducting a mock evacuation during our onsite survey. A mock evacuation is especially important when the evacuation route is not over a flat surface, but rather sloped, because the time taken for evacuation on such a road is longer than the time estimated using the average walking speed of adult males which is $1.4 \mathrm{~m} \mathrm{~s}^{-1}$.

\subsection{Emergency action plan for ports and ships}

The key information about a port should be collected prior to setting up a detailed EAP. The Ministry of Oceans and Fisheries operates a Port Management Information System and provides statistical data regarding the vessels entering and leaving each harbor, and the cargo handled. The information regarding cargo is important to know in order to estimate the damages and to respond accordingly if tsunamis strike cargo wharves. Floating containers in container wharves can cause secondary damage after tsunami events.

The tsunamis that occur in port areas push the vessels at berth onto land and cause them to collide into port facilities, giving rise to secondary damage. If the estimated time for the tsunami arrival is longer than the time required to reach an area of the sea that is safe from the tsunamis, then ships should be steered to that area and remain there during a tsunami strike. For the ships in an area of the sea deeper than $400 \mathrm{~m}$ (UNESCO-IOC and ITIC, 2009), it is safer to stay at sea than to enter the harbor in order to berth. However, if a tsunami is imminent, no attempt should be made to navigate offshore to a safe sea area, because that would cause a risk to life. It should also be taken into consideration that vessels will advance more slowly than usual to open sea due to the mass exodus of hundreds of vessels.

Figure 4 shows the distances to water deeper than $400 \mathrm{~m}$ at each harbor. Given that a tsunami near the western coast of Japan generally takes between $90-120 \mathrm{~min}$ to reach the eastern coast, the duration of 28-55 min is long enough for ships at Guryongpo Port to evacuate to safe open seas, as shown in Fig. 5. This time was estimated based on the usual speed of a freight ship, which is $10-20 \mathrm{kn}$.

During the Great East Japan Tsunami which occurred on 11 March 2011, an oil tank used for fishing boats was toppled by the tsunami and it caught fire, causing severe fire damage. Proper measures to prevent similar secondary damage should be included in an EAP, because oil tanks for vessels are ubiquitous in ports. As much as possible, it is recommended to install and operate oil tanks in areas safe from tsunami inundation, which can be determined through numerical model experiments that simulate a tsunami. Oil tanks should be emptied as soon as a tsunami warning is issued.

If a tsunami warning is issued, then harbor masters should immediately inform all of the companies within their harbor areas and mobilize enough people to carry out the tasks required for the tsunami evacuation, such as mooring ships, hauling and attaching floating objects, and transporting important materials. In particular, any empty containers in the container terminals should be fastened in order to prevent them from freely floating and causing secondary damage.

The Vessel Traffic Center should provide timely information on the sea and land conditions within its jurisdiction areas. The Vessel Traffic Service (VTS) system serves as the basis for making these navigation decisions. One of its important tasks is to take rapid initial measures and to propa- 
gate situation conditions during marine safety accidents and emergencies. Therefore, all of the ships should be tuned to the VTS channel and they should follow their directions in order to move towards an area of the sea that is safe from tsunamis (i.e., a water depth greater than $400 \mathrm{~m}$ ).

Table 4 shows an overview of the channels that the VTS system uses. In particular, the Vessel Traffic Center recommends listening to channel 12, which provides information on navigational safety, harbor operations, and special weather reports within the VTS area. Channel 16 provides information on tsunami warnings and situations related to distress, urgency, safety, emergency communications, calls, and responses. The evacuation situations of fishing vessels at sea should be checked using the Fishery Information and Communication Station's channel, and the use of these communication channels should be proactively encouraged in order to maximize accident prevention.

Table 5 lists the frequencies of the tsunami responses at Busan Port and Ulsan Port fishery information and communication station. This information enables vessels to get any assistance in emergency situations.

\subsection{Transport of movable port equipment}

A transportation plan for movable port equipment and materials can greatly influence post-tsunami operations. If enough time remains before the arrival of the first tsunami, all of the documents related to harbor operations in the form of digital storage media should be moved to safe places. The same applies to movable, expensive machines and other equipment that is necessary for harbor operations. The transported equipment should be stored in predetermined shelters at an elevation of approximately $10 \mathrm{~m}$ with large parking areas in order to ensure enough space and safety. The criteria for choosing a transport route are the speed and safety of the route (i.e., it should be the shortest route that is free of obstacles). In cases where the transportation route overlaps the evacuees' walking path, control personnel should be assigned in order to ensure safety.

\subsection{Hazard map}

An effective and economic way for tsunami mitigation planning is to construct a hazard map along the coastline vulnerable to unexpected tsunami invasion. To produce a reliable hazard map, it is necessary to employ a numerical model that simulates accurately a distant propagation of tsunamis from a source region of an undersea earthquake to a coastal community. The numerical model may exclude the nonlinear effects but include the frequency dispersion (Cho and Yoon, 1998).

In Fig. 5, a tsunami hazard map is displayed at Imwon Port. The map is made by numerically simulating historical tsunami events and projected scenarios (Shin et al., 2013). The map covers precautions, evacuation routes, shelters and some information of tsunami and earthquakes. Emergency contact telephones and legend display are also included. As shown in Fig. 1, two historical tsunamis attacked the Korean Peninsula were triggered by undersea earthquakes occurred near the western coast of Japan. Thus, in this study, the tsunami response system is made based on tsunamis generated near the western coast of Japan. The developed hazard map could be used by the civil defense organization to make an evacuation plan in the event of a real tsunami attack.

\section{Conclusions}

In this study, we established a tsunami response system by improving the existing emergency action plans tailored to each harbor. We conducted a comprehensive study using scientific reasoning that embraced all of the administrative procedures from issuing warnings to post-tsunami measures. While the government, local governing bodies, and related institutions have established EAPs to respond rapidly to marine disasters in order to minimize the loss of human lives and property, harbor-specific EAPs created on basis of expert tsunami research are still lacking. Therefore, we drew on our understanding of tsunami characteristics in order to analyze the drawbacks of an existing tsunami response system and we sought to establish methods to improve the efficiency of the application in each of the harbors.

A tsunami response system is set up with separate guidelines for all of the stakeholders, including residents, harbor operators and workers, and related government officials. The tsunami response system may contribute to a natural disaster prevention research in future. In particular, it is our hope that it will serve as a basis for establishing an EAP uniquely tailored to each of the port's characteristics, thus contributing to a more rapid and efficacious response to coastal disasters. Although the risk analysis of tsunamis is not included in this study, the topic is significant and related studies can be found in other literature (Kim et al., 2012; Cho et al., 2013).

Acknowledgements. This research has been supported by the Korea Institute of Marine Science and Technology Promotion [Reference No. 20130264].

Edited by: H. Hebert

Reviewed by: three anonymous referees

\section{References}

Cho, Y.-S.: Numerical Simulations of Tsunami Propagation and Run-up, PhD. Thesis, Cornell University, USA, 1995.

Cho, Y.-S. and Yoon, S. B.: A modified leap-frog scheme for linear shallow-water equations, Coast. Eng. J., 40, 191-205, 1998.

Cho, Y.-S., Jin, S.-B., and Lee, H.-J.: Safety analysis of Ulchin Nuclear Power Plant against the Nihonkai-Chubu Earthquake Tsunami, Nuclear Eng. Design, 228, 393-400, 2004. 
Cho, Y.-S., Kim, Y.-C., and Kim, D.-K.: On the spatial pattern of the distribution of the tsunami run-up heights, Stochast. Environ. Res. Risk Asses., 27, 1333-1346, 2013.

Japanese Review Committee of Tsunami Response Manual: Report on the Review Committee of Tsunami Response Manual, 2002.

Kim, Y.-C., Choi, M., and Cho, Y.-S.: Tsunami hazard area predicted by probability distribution tendency, J. Coast. Res., 28, 1020-1031, 2012.

Shin, J., Han, S., and Cho, Y.-S.: Production of tsunami hazard map, Proceedings of the 35th International Association for HydroEnvironment Engineering and Research, 321, 1-7, China, 2013.
Sohn, D.-H., Ha, T.-M., and Cho, Y.-S.: Distant tsunami simulation with corrected dispersion effects, Coast. Eng. J., 51, 123-141, 2009.

UNESCO-IOC and ITIC: Tsunami Teacher (DVD), available at: http://itic.ioc-unesco.org/index.php?option=com content $\&$ view $=$ article $\&$ id $=1441$, (last access: 27 February 2015), 2009. 